\title{
Gendered Phenomenological Perceptions of Parents and Learners on Comprehensive Sexuality Education in Military Aided Schools of Eastern, Zambia
}

\author{
Anne Namakando-Phiri", Mubiana Macwan'gi, John Mwitumwa Matakala, Lizzy Peter \\ machina \\ Department of Gender Studies, University of Zambia, Lusaka; Zambia
}

*Corresponding Author: Anne Namakando-Phiri, Department of Gender Studies, University of Zambia, Lusaka; Zambia

\begin{abstract}
This study was aimed at exploring and understanding the gendered phenomenological perceptions of parents and learners on comprehensive sexuality education in military aided schools of eastern, Zambia. The motivation behind this study is to understand the views on the implementation impact of comprehensive sexuality education based on gendered views of learners and parents. In order to understand the experiences, the study made use of a qualitative inquiry grounded in existential phenomenology.

Purposive Sampling using Snow ball sampling was used to come up with the desired sample size of 20 and the resultant data that were collected. Data collection was achieved by use of in-depth interviews. The data were analyzed using phenomenological analysis in order to transcribe the bulk data into themes and sub themes.

The findings were categorized in line with the objectives of the study which where (a) Nature of Sexual Harassment (b) Coping mechanisms in the face of Sexual Harassment and (c) Regulatory measurers put in place to curb Sexual Harassment.

The findings of the study on the nature of sexual harassment using in - depth interviews show that female and male soldiers of the junior ranks experience Sexual Harassment as opposed to the senior ones. Further, revealed is that the nature of Sexual Harassment experienced mostly is verbal Sexual Harassment which is dominant and manifesting itself in form of unwanted gendered comments. Nonverbal sexual harassment through unwanted actions was a further experience for the females. It was further found out that the junior soldiers experienced these vices at platoon level from corporals and sergeants.

The findings of the study on coping of soldiers in the face of sexual harassment revealed that sexual harassment was common. Furthermore, although there was only one standard way of reporting problems to relevant authorities, the issue of sexual harassment was not taken seriously. Further findings, indicate that the junior soldiers practiced coping mechanisms which are problem fixing, where they befriend a senior officer for protection and problem sharing were they shared with a friend to lighten the stress.
\end{abstract}

The findings on regulatory measures put in place to curb sexual harassment show that there is no written instruction in the Army and indeed the United Nations hence making it difficult for soldiers to be protected.

The gendered work output may go down if the issue remains unchecked leading to low morale. It is against this background that in order to improve the situation a number of recommendations have been put forward for consideration by the Army Education Directorate and Ministry of General Education.

Keywords: Gendered Phenomenological Prceptions, Comprehensive Sexuality Education, Miltary Aided Schools, Parents and Learners.

\section{INTRODUCTION}

\subsection{Background to the Study}

Comprehensive Sexuality Education implementation in both private and public schools has become one of the gender issues that is presently of great concern not only in schools of many communities, but also not of exclusion are the military aided school communities. Largely this is because of the negativity toward its implementation. Early engagement into sexual intercourse among adolescents is on the increase not only in many societies but also among school going children, leading to 
international bodies proposing the introduction of comprehensive sexuality education in the world today including Zambia UNESCO, (2009).

Zambia is one of the countries that is also an affiliate to the international bodies such as the United Nations therefore, this is a concern that affects our schools. In 2013 the school curriculum in Zambia was revised to include aspects of comprehensive sexuality education in all primary school subjects in order to expatriate awareness among learners MOE, (2013).

Despite the efforts made by the United Nations and many countries the issue of implementation of comprehensive sexuality education is viewed negatively.

Reading through empirical literature shows that there has since been a reaction by many research studies which among others include Fentahun, 2012; Passag, 2015; Dawn, 2014; Mark, 2011; Mahajan and Sharma, 2005; Savitry, 2015; and Bhuyan, 2014.

An interaction with empirical literature above show that the studies focus regarding the subject was on either the teachers and learners or separately. However, there are few studies that concentrated on the parents as a separate entity.

From the reviewed literature it appears none of the research studies combined the parents and the learners in trying to address the issue of comprehensive sexuality education.

The motivation behind this inquiry is to ensure that gendered views from both the parents and learners are taken into consideration to ensure gender equality from both stakeholders.

Owing to the background the identified knowledge gap is explained explicitly under the statement of the problem.

\subsection{Statement of the Problem}

Gendered Phenomenological Perceptions of parents and learners on Comprehensive Sexuality Education in military aided schools of eastern, Zambia has not been done.

This is a compelling knowledge gap.

\subsection{General Objective}

To explore and understand the gendered phenomenological perceptions of parents and learners on Comprehensive Sexuality Education in military aided schools of eastern, Zambia.

\subsection{Specific Objectives to}

- To establish the gendered phenomenological perceptions of learners on the benefits of learning comprehensive sexuality education.

- To identify the gendered phenomenological perceptions of learners and parents on the Challenges of learning of comprehensive sexuality education.

\subsection{Research Questions}

- What are the gendered phenomenological perceptions of learners on the benefits of learning comprehensive sexuality education?

- What are the gendered phenomenological perceptions of learners and parents on the Challenges of learning of comprehensive sexuality education?

\subsection{Significance of the Study}

This study is not only going to add knowledge to the discipline of Gender Development Studies at the University of Zambia but will further avail information to both the policy implementers both in the military that is Education Directorate and the Ministry of General Education. It is also hoped that it will act as a stepping stone for further research.

\subsection{Ethical Consideration}

The study sought for, dual permission involving the military authorities and the actual participants. 


\subsection{Definition Of Terms}

- Comprehensive Sexuality Education: is a lifelong learning of acquiring information and forming attitudes, beliefs and values which addresses age appropriate physical, mental, emotional and social dimension of human sexuality education.

- Gendered Phenomenological Perceptions: A combination of Female/Male (parents/learners) and their lived experiences based on how they view the issue.

- Military Aided Schools: These are schools that are located in the military barracks under the administration of a commissioned officer from the Army.

\subsection{Purpose Statement}

The purpose of this Existential Phenomenological inquiry was to uncover the meaning, articulated 'essences' of gendered phenomenological perceptions of parents and learners as a way of understanding the lived experiences on comprehensive sexuality education in the military aided schools of eastern part of Zambia.

This approach facilitated the fast eliciting, of every day gendered phenomenological perceptions and ideas of the participants from the insider's view called the 'emic' perspective Holloway and Wheeler (1996). It further assisted in the articulation and amplification of the views of both the learners and parents as stakeholders.

Methods of inquiry included a phenomenological reflection on data elicited by existential investigation of learners and parents' experiences and investigation of the phenomenon in the creative arts Creswell (2009).

\section{MeThodology}

A qualitative research approach was used grounded in the philosophy of Interpretivism in order to understand the Gendered experiences and interpretations of learners and parents on their views in terms of the implementation of comprehensive sexuality education in military aided schools of eastern Zambia. The research design that was used was the Existential phenomenology to get down to the Gendered Phenomenological Perceptions of the participants as well as allowing the researcher to bracketing his ideas by only getting views of participants Egaden (2012). This is a Husserlian approach whose major proponent was Edmund Husserl.

The present study adopted the title and the research design from the study of Matakala E'tal (2018) that looked at the topic[Gendered Phenomenological Perceptions On Characteristics of Sexual Harassment Among Soldiers In Eastern, Zambia] in the international journal of humanities social sciences and education volume 5 issue 7, July 2018, p 93-101. The justification for the choice in the methodology is because one of the characteristics of research is that it is the replicability and transmittable, since the observations and explanations are logical making it possible for anyone to use and get the desired results. Furthermore, the methodology can be verified and validated in the inquiry Bless and Achola (1988).

The study was conducted in the military aided schools of eastern part of Zambia, among parents that had children at the military aided schools and the learners. Judgmental and Snowball sampling were used to come up with the desired sample size of 20 in the absence of the sampling frame. The study had ten parents that were equal between the male and female. Furthermore, the learners were ten with an equality figure between the male and female.

The sample size is justified because it fits into a qualitative inquiry because data saturation issues. This is arrived at when no newer data is forth coming usually happening between one to three participants. Therefore, the four strata were ideal in this study for male and female categories of the parents and learners.

The resultant data were collected through the in-depth interview guides and the data collection procedure began with the pretest, prescribed interview process and sequential actual data collection was used on the two objectives. 
Pretest. Before the actual data collection, the interview guide was subjected to prior collection so as to standardize the research instruments so that they are able to collect the desired information.

Interview process. The participants were first greeted by the researcher. They were later told the purpose of the study and consent was gotten from them before the inquiry. They were also assured of confidentiality and that they had a right to pull out at any time they felt uncomfortable as it was there right before commencement of the interview or after.

Sequential transformative strategy. Was used to collect the data because the objectives were followed chronologically and were both qualitative by nature Creswell (2009).

The findings were thermalized chronologically in line with the first objective which was on the benefits of learning comprehensive sexuality education from learners and the challenges of teaching comprehensive sexuality education from both learners and parents.

The data were analyzed by the use of the phenomenological data analysis by reducing the large amounts of data by transcribing each script in order to come up with the themes and sub themes of the inquiry. Furthermore, issues of trustworthiness were achieved through Guba's four trustworthy strategy of credibility, dependability, transferability and Confirmability. It falls under the volunteristic axiology which looks at ethics and aesthetics which looks at the value of the study academically. Guba and Lincoln (1994).

Credibility. Was ensured by choosing of the correct research design or plan which was the existential phenomenology hence the data is correct and is acceptable academically.

Dependability. Was done through standardizing the research instruments so that they get the desired information hence the data is correct and is acceptable academically.

Confirmability. Was done by ensuring the phenomenological reduction or 'epoche' or bracketing of pre conceived ideas through listening and taking the information as it comes.

(1) Transferability. Was done through the afore mentioned in that the study has the capacity of being contextualized with other studies so as to come up with similarities which can lead to identification of gaps by other studies.

How Did The Researcher Maintain Research Confidence From The Researched (Participants) In The Inquiry?

This was achieved through the use of reading the informed consent form which is shown hereunder.

\subsection{Informed Consent Form}

Dear participants,

This serves to give you an understanding of the research and procedures that will be followed.

Similar information in this form will be read to you alongside the questions with regard to each objective and its research instrument.

Further the implications for your participation are explained below, finally you are asked to sign this form to indicate that you have agreed to participate in this exercise.

Thanking you in advance.

\subsubsection{Description}

This is an educational research; the researchers are at the University of Zambia under the Gender Studies department.

This research is a contribution to academic knowledge. Therefore, this study is purely academic.

\subsubsection{Purpose}

The researchers wish To explore and understand the gendered phenomenological perceptions of parents and learners on Comprehensive Sexuality Education in military aided schools of eastern, Zambia and it is going to be purely a phenomenological perspective under the Interpretivism philosophy or paradigm. The researchers are interested in establishing the gendered 
phenomenological perceptions of learners on the benefits of learning comprehensive sexuality education and identifying the gendered phenomenological perceptions of learners and parents on the Challenges of learning of comprehensive sexuality education.

\subsubsection{Consent}

Participation in the exercise is voluntary. You are free to decline to participate in this exercise.

\subsubsection{Confidentiality}

All data collected from this research is treated with utmost confidentiality. Participants are assured that they will remain anonymous and untraceable in this research.

It is against this background that participants will only be identified through a number and not by name or pseudo names will be used.

\subsubsection{Rights of participants}

All efforts will be taken to ensure that the rights of participants as per research ethics are protected and respected. Participants are assured that they are free to ask for clarification at any point of the exercise and to inform the researcher if they feel uncomfortable about any procedure in the research.

Your consent to this request will be highly valued and appreciated.

\subsubsection{Declaration of Consent}

I have read or head and fully understand this document concerning the research. Therefore voluntarily I have agreed to participate in this study.

Participant number Signature

Date:

Adapted from Holloway and Wheeler (1996)

\section{RESUlTS \& DisCUSSION}

\subsection{What are the Gendered Phenomenological Perceptions of Learners on the Benefits of Learning Comprehensive Sexuality Education?}

\subsubsection{Contextualised Similarities With Other Empirical Studies}

\begin{tabular}{|l|l|}
\hline $\begin{array}{l}\text { Empirical Findings on benefits of learning } \\
\text { comprehensive sexuality education from } \\
\text { Literature Review }\end{array}$ & $\begin{array}{l}\text { Research Findings on the benefits of learning } \\
\text { comprehensive sexuality education for this Study }\end{array}$ \\
\hline $\begin{array}{l}\text { A Study by Fentahum; (2005) found out that } \\
\text { learning of comprehensive sexuality education }\end{array}$ & $\begin{array}{l}\text { The findings of this study are in agreement with } \\
\text { the other studies that were conducted by }\end{array}$ \\
$\begin{array}{l}\text { was beneficial in that it leads to enhanced } \\
\text { knowledge on the consequence of sex. }\end{array}$ & $\begin{array}{l}\text { Fentahum and Dawn. } \\
\text { - Another study by Dawn; (2014) found out that } \\
\text { one of the benefits of learning sexuality } \\
\text { education is that it avoids contraction of } \\
\text { diseases. }\end{array}$ \\
\hline
\end{tabular}

Source: Field Data (2018) and Empirical Literature

This is what the participants had to say when asked what the benefits of learning Comprehensive Sexuality Education;

A female grade nine girl by the name of Violet (Pseudo Name) when asked on the benefits of learning Comprehensive Sexuality Education had this to say;

'Sir 'meaning the researcher' the new subject makes me to learn

and be aware of the consequences of having sexual intercourse.

For me being able to make decisions at least I will know that

The result of my actions will be costly 
A male grade eight boy by the name of Jimmie (Pseudo Name) when asked on the benefits of learning Comprehensive Sexuality Education had this to say;

"Sir 'meaning the researcher' learning of Comprehensive Sexuality

Education is beneficial to me as a grown up boy because diseases

That result from sexual intercourse are taught therefore I can easily

Avoid contraction of diseases such as (bolabola)(in english gonoreah) don't

KnoIt in English but pus is discharged from private parts"

\subsubsection{Contextualised Disimilarities with Other Empirical Studies}

This study did come up with findings that showed that learners, said that learning comprehensive sexuality education was beneficial because it made them know the protection measures so that they don't contract veneral diseases and avoid pregnancies by using condoms respectively hence this was new knowledge contributed to the academia world unlike other studies. The reason for this difference is differential modes of learning.

This is what the participants had to say when asked what the benefits of learning Comprehensive Sexuality Education;

A male grade nine boy by the name of Francis (Pseudo Name) when asked on the benefits of learning Comprehensive Sexuality Education had this to say;

"Sir 'meaning the researcher' learning of Comprehensive Sexuality

Education is beneficial to me because I have learnt that if I do

Sexual intercourse with the girl with a condom she can't be

Made pregnant ........................................."

A female grade eight girl by the name of Lizzie (Pseudo Name) when asked on the benefits of learning Comprehensive Sexuality Education had this to say;

'Sir 'meaning the researcher' the new subject me to learn and be aware of the consequences of having sex with a boy will make me to be sick hence I carry a male condom to give him to wear that makes me avoid veneral diseases and being made pregnant"

3.2. What are the Gendered Phenomenological Perceptions of Learners and Parents on the Challenges of Learning of Comprehensive Sexuality Education?

3.2.1. Contextualised Similarities with Other Empirical Studies

\begin{tabular}{l|l|}
\hline $\begin{array}{l}\text { Empirical Findings on the challenges of learning } \\
\text { comprehensive sexuality education from Literature } \\
\text { Review }\end{array}$ & $\begin{array}{l}\text { Research Findings on the challenges of learning } \\
\text { comprehensive sexuality education for this } \\
\text { Study }\end{array}$ \\
\hline $\begin{array}{l}\text { A Study by Fentahum; (2005) found out that the } \\
\text { challenge of learning of comprehensive sexuality } \\
\text { education is that it may encourage children to } \\
\text { experiment. }\end{array}$ & $\begin{array}{l}\text { The findings of this study are in agreement } \\
\text { with the other studies that were conducted by } \\
\text { Fentahum and Dawn. }\end{array}$ \\
$\begin{array}{l}\text { Another study by Dawn; (2014) found out that } \\
\text { one of the challenges of learning c sexuality } \\
\text { education is that it conflicts with cultural accepted } \\
\text { norms. }\end{array}$ & $\begin{array}{l}\text { The study findings are similar because } \\
\text { culture tends to be universal in certain areas } \\
\text { of social interactions. }\end{array}$ \\
\hline
\end{tabular}

Source: Field Data (2018) and Empirical Literature

This is what the participants had to say when asked what the challenges of learning Comprehensive Sexuality Education;

A female mother to a grade nine girl by the name of Patricia (Pseudo Name) when asked on the challenges of learning Comprehensive Sexuality Education had this to say; 
'Sir 'meaning the researcher' the new subject makes my heart bleed

Because maturity for girls comes early and I fear for my girl child

Who might wish to practice what is being learnt ......................"

A male father of the rank of staff sergeant for grade eight boy by the name of Jimmie (Pseudo Name) when asked on the challenges of learning Comprehensive Sexuality Education had this to say;

"Sir 'meaning the researcher' learning of Comprehensive Sexuality

Education has a challenge in that for me it is taboo to talk about the

Issue of sex...... fyamuselu in Bemba meaning it is detestable......."

\subsubsection{Contextualised Disimilarities with Other Empirical Studies}

This study did come up with findings that show that one of the challenges of the learning of comprehensive sexuality education was the feeling of discomfort feeling when it is being taught to the learners and overcrowding classes. The other challenge is that there had been lack of sensitization hence lack of support for the subject from the parents. The reason for this difference is differential modes of learning and additionally.

A female grade nine girl by the name of Patricia (Pseudo Name) when asked on the benefits of learning Comprehensive Sexuality Education had this to say;

'Sir 'meaning the researcher' the new subject always makes me

Me feel uncomfortable and the class I learn from is always

Over crowded with other boys and girls of different ages....

When certain points are stressed such as

A female mother to a grade eight girl by the name of Linda (Pseudo Name) when asked on the challenges of learning Comprehensive Sexuality Education had this to say;

'Sir 'meaning the researcher' the new subject has not been told

To me as a parents in terms of the depth of content and we fear

That it can corrupt the minds of my children

We can not support it because the school authorities have

Not sensitized us.

A male father of the rank of sergeant for grade nine boy by the name of Norman (Pseudo Name) when asked on the challenges of learning Comprehensive Sexuality Education had this to say;

"Sir 'meaning the researcher' learning of Comprehensive Sexuality

Education has a challenge in that I did not know that the children are

Are being the subject that involves sex including the depth of language

That is used.... hence for me supporting it......."

\section{CONCLUSION}

The conclusion of the whole matter is that this study will avail information to the policy makers for policy implementation from the findings of the out lined research questions.

- What are the gendered phenomenological perceptions of learners on the benefits of learning comprehensive sexuality education?

- What are the gendered phenomenological perceptions of learners and parents on the Challenges of learning of comprehensive sexuality education?

The findings for research question one show that the benefits of the teaching and learning of comprehensive sexuality education it leads to enhanced knowledge on the consequences of sex with 
regard learners as they interact. It also avoids contraction of diseases among the learners as they do their social interactions and further avoids pregnancies in the girls.

The findings for research question two show that the challenges of the teaching and learning of comprehensive sexuality education is that it may encourage experimentation among the children which might lead to contraction of diseases. It is not supported by parents because of lack of sensitization by the school authorities.

Owing to this conclusion there is a need of proposing of recommendations based on the researcher perspective to mitigate the problem so as to inform policy.

\section{RECOMMENDATIONS}

In view of the important role that is attached to the subject of comprehensive sexuality education in terms of promoting helpful knowledge on the issues related to indulgence in sexual intercourse, there is a need for conceited efforts by stake holder such as the ministry of general education and the school authorities to implement the proposed recommendations of this study. The findings of this study inform the ministry of general education in Zambia to find lasting policy that should mitigate the teaching and learning of comprehensive sexuality education improvement, that will not only better it here in Zambia but also other schools globally.

This should be done in the most effective and sufficient manner as suggested below by the researchers or authors. Presented below are the proposed recommendations.

- The ministry of general education should ensure that it comes up with a deliberate policy which will ensure that the subject of comprehensive sexuality education should be independent and fall under its own association with trained teachers.

- The ministry of general education should go into a memorandum of understanding (Mou) with Non-Governmental Organizations (Ngos) that are ready to assist in the subject. This idea must also be encouraged at school level.

- The school authorities should also be required to sensitize the parents on the salient issues that are taught to the parents during the parent's teacher association meetings in order to solicit for there support.

\section{Recommendations for Further Studies}

It is recommended that that a future study must consider undertaking a mixed methods study in order to have both a general and in-depth understanding of the teaching and learning of comprehensive sexuality education.

\section{ACKNOWLEDGEMENT}

I wish to thank the other the other main author Prof. Mubiana Macwan'gi for the academic contribution. I further thank all the Lecturers in the Department of Gender Studies for their advice. I also on behalf of my other co-author John Mwitumwa Matakala thank the Army Commander General Paul Mihova and Brig General Francis Kasempa from Special forces (Commando) and the rest of Command at different levels for their support and blessings. Not be left out is Colonel John Banda. Special thanks goes to the administrators of the military aided schools in eastern Zambia.

\section{REFERENCES}

[1] Bilinga, M and Mabula, N. (2014). Teaching Sexuality Education in Primary Schools in Tanzania: Challenges and Implications. Journal of Education and Practice vol 5 no 27, 2014.

[2] Buga, G. D. Et al (1996).Sexual Behaviour, Contraceptive Practice and Reproductive Health among School Adolescents in Rural Transkei. South African Medical Journal.86(5), 523-527.

[3] Bhuyan, M.K. (2014). Inclusion of Sex Education in School Curriculum of Bangladesh: Parents Attitude. Journal of Research and Methods in Education Vol4 no5 2014 pp32-40

[4] Creswell, J. W. (2003). Research Design, Qualitative, Quantitative and Mixed Methods Approaches. London: Sage.

[5] Dawn, R.C. (2014). Learners Perceptions of sexuality education: A study of secondary learners in Montreal,McGill University publishers, Quebec. Egaden S J, (2012). A Modern thought on advanced research and innovation: Developing of Toolkits and participatory action, penguin publishers,London. 
Gendered Phenomenological Perceptions of Parents and Learners on Comprehensive Sexuality Education in Military Aided Schools of Eastern, Zambia

[6] Holloway, I and Wheeler, S. (1996). Qualitative research for Nurses Hartinolis limited, Paris

[7] Kombo, D. K. and Tromp, L. A. (2006). Proposal and Thesis Writing: An Introduction, Pauline Publication Africa, Nairobi.

[8] Krueger, R. A. (1988). Focus Groups and Interviews: A practical Guide for Applied Research Methods. Sage Publishers, London.

[9] Leedy, P. and Omorod, E. (2005). Practical Research Planning and Design. Merrill Prentice Publishers, New Jersey.

[10] Malekinejad, M; Johnston L G; Kendall C; Kerr L R; Rifkin M R and Rutherford G W (2008) Using Respondent-Driven Sampling Methodology for HIV Biological and Behavioral Surveillance in International Settings: A Systematic Review. AIDS and Behavior, 12, S105-S130.

[11] Fentahum, N. Assefa, T. Alemseged, F and Ambaw, F. (2012). Perception, Student and Teachers' Attitude Towards Sex Education. Ethiopia journal Health Science 22(2):96-106

[12] Guba, E and Lincoln, Y. (1994). Qualitative Research, Sage Publications, London.

[13] Mohammed, G. (2014). Atlas T17 Qualitative Data Analysis Software: Principles and Practice, Penguin Publishers, New York.

[14] Msabila, T. and Nalaila, G. (2013). Research Proposal and Dissertation Writing: Principles and Practice, Nyambari Publishers, Dar es Salaam.

[15] Passag, K. (2005). Study on attitudes of teachers and students towards the teaching of sex education among secondary schools in Timphur, Bhutan publishers, Tinidad.

[16] Savitri , E. (2015). Teaching Sexuality and Sexual Health at a Rural Government Primary School in The North Eastern Education District: Parents Concerns. University of West Indies.

[17] United Nations Education Scientific and Cultural Organisation. (2015). Comprehensive Sexuality Education: The impact on the lives of the young People.

[18] United Nations Education Scientific and Cultural Organisation. (2014). Comprehensive Sexuality Education: The Challenges and Opportunities of Scaling-up.

[19] United Nations Education Scientific and Cultural Organisation and United Nations Population Fund. (2014). Operational Guidance for Comprehensive Sexuality Education: A Focus on Human Rights and Gender.

[20] United Nations Education Scientific and Cultural Organisation. (2009). UNESCO International Guidelines On Sexuality Education": AnEvidence Informed Approach to Effective Sex Relationships and HIV/STI Education. (Draft). Available at: http://www.unesco.org/aids [accessed 10/02/2017].

[21] United Nations Population Fund. (2014). The Commission on Population and Development (CPD) and UNESCO's International Technical Guidance on Sexuality Education (ITGSE).

[22] United Nations Population Fund (UNFPA) (2014). Comprehensive Sexuality Education. United Nations Population Fund 605 Third Avenue New York, USA.

[23] United Nations. (1948) .The Universal Declaration of Human Rights .Available at: http://www.un.org/en/ documents/udhr/index.shtml [accessed 2 Feb. 2017].

[24] Vergnani, T. and Frank, E. (1998). .Sexuality Education for Senior Phase (Grades 7-9) parents. Heinemann.

\section{AUTHOR's BIOGRAPHY}

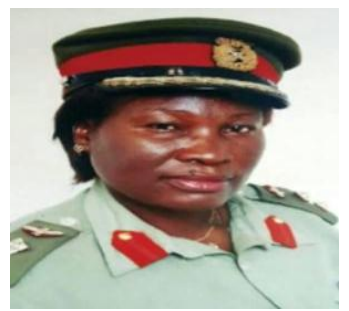

Dr. Annie Namakando -Phiri (Col), the Doctor of Public Healthy /Epidemiology/ Gender. She is also a Senior Retired Army Officer, was a Head of Department (Gender Studies) - 2013 To 2016 at the University of Zambia. She is a Research and Phenomenological Advisor and Main Resercher in this Inquiry. Senior Lecturer/Researcher - Department of Gender Studies.

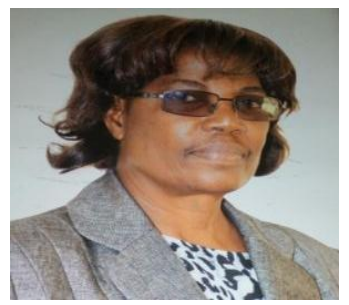

Prof. Mubiana Macwan'gi, the Professor of Public Health and Behavioral Scientist Was The Institute of Economic and Social Research Director - 2010 to 2016 at the University of Zambia. She is also one of the Main Researchers and Advisor in this Inquiry. Recently, She Received, the Most Outstanding Female Researcher Award at the 8 th Health Research Conference. Senior Lecturer/Researcher - Department of Gender Studies. 
Gendered Phenomenological Perceptions of Parents and Learners on Comprehensive Sexuality Education in Military Aided Schools of Eastern, Zambia

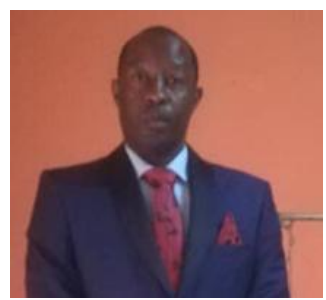

John Mwitumwa Matakala, a Doctor of Philosophy Reasearch Fellow in Gender Studies at the University of Zambia. He is an Assistant Researcher in this Inquiry.

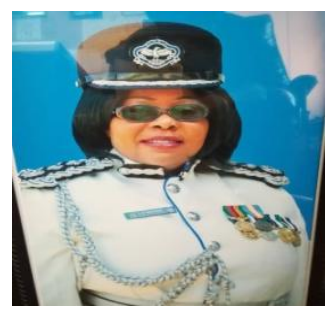

Lizzy Peter machina, She is Master of Arts with Gender and Researcher at the Zambia Open University, She is a Commissioner of Police and Commanding Officer Airport Division and She is an Assistant Researcher in this Inquiry.

Citation: Anne Namakando-Phiri, et.al. "Gendered Phenomenological Perceptions of Parents and Learners on Comprehensive Sexuality Education in Military Aided Schools of Eastern, Zambia" International Journal of Humanities Social Sciences and Education (IJHSSE), vol 5, no. 12, 2018, pp. 41-50. doi: http://dx.doi.org/10.20431/2349-0381.0512005.

Copyright: (C) 2018 Authors. This is an open-access article distributed under the terms of the Creative Commons Attribution License, which permits unrestricted use, distribution, and reproduction in any medium, provided the original author and source are credited. 